\title{
Research Article \\ Effect of Neodymium Nanoparticles on Elastic Properties of Zinc-Tellurite Glass System
}

\author{
Abdulbaset A. Abdulla Awshah, ${ }^{1}$ Halimah Mohamed Kamari, ${ }^{1}$ \\ Chan Kar Tim, ${ }^{1}$ Nurisya Mohd Shah, ${ }^{1}$ S. H. Alazoumi, ${ }^{1}$ \\ Umar Saad Aliyu, ${ }^{1,2}$ and Muhammad Noorazlan Abd Azis ${ }^{1}$ \\ ${ }^{1}$ Physics Department, Faculty of Science, Universiti Putra Malaysia (UPM), 43400 Serdang, Selangor, Malaysia \\ ${ }^{2}$ Department of Physics, Faculty of Science, Bauchi State University, Gadau, Nigeria
}

Correspondence should be addressed to Halimah Mohamed Kamari; hmk6360@gmail.com

Received 14 February 2017; Revised 20 June 2017; Accepted 9 July 2017; Published 29 August 2017

Academic Editor: Cristina Leonelli

Copyright (C) 2017 Abdulbaset A. Abdulla Awshah et al. This is an open access article distributed under the Creative Commons Attribution License, which permits unrestricted use, distribution, and reproduction in any medium, provided the original work is properly cited.

\begin{abstract}
The aim of this work is to determine the effect of neodymium nanoparticles concentration on the elastic properties of zinc-tellurite glass. A series of neodymium nanoparticles doped zinc-tellurite glass systems (NdNPsZT) of composition $\left[\left(\mathrm{TeO}_{2}\right)_{0.70}(\mathrm{ZnO})_{0.30}\right]_{(1-x)}\left(\mathrm{Nd}_{2} \mathrm{O}_{3} \mathrm{NPs}\right)_{(x)}, x=0.01,0.02,0.03,0.04$, and 0.05 , were synthesized by using conventional meltquenching method. The amorphous nature of the glass system was confirmed by using XRD analysis. The density of the glass system was determined by Archimedes method. The elastic properties were calculated from the measured density and ultrasonic velocity at $5 \mathrm{MHz}$ frequency. The experimental results showed that the elastic properties rely upon the composition of the glass systems and the impact of neodymium nanoparticles $\left(\mathrm{Nd}_{2} \mathrm{O}_{3} \mathrm{NPs}\right)$ within the glass network. The increase in ultrasonic velocities is due to the increase in rigidity and change in structural units of the glass system. The softening temperature and the microhardness increased with the increase in $\mathrm{Nd}^{3+}$ ions concentration from 0.1 to $0.2 \mathrm{~mol}$ and decreased when the $\mathrm{Nd}^{3+}$ ions concentration increased from 0.2 to $0.5 \mathrm{~mol}$. Poisson's ratio and Debye's temperature decreased with the increase in the $\mathrm{Nd}^{3+}$ ions concentration from 0.1 to $0.2 \mathrm{~mol}$ and increased when the $\mathrm{Nd}^{3+}$ ions concentration was increased from 0.2 to $0.5 \mathrm{~mol}$.
\end{abstract}

\section{Introduction}

Tellurite glasses were found to be interesting glasses due to their unique properties and applications $[1,2]$. The glass science and technology have found so much interest in tellurite glasses over the years. This may be due to their low melting points, high refractive indices, high dielectric constants, and good infrared transmission $[3,4]$. Tellurite glass doped with nanoparticles system has found great interest, mostly in the study of the effect of nanosize particles on optical behavior [2].

Tellurite glasses have also been employed for the synthesis of metallic nanoparticles (NPs) and for the enlargement of metallic NPs. This is especially in the design of simple and sensitive electrochemical and optical sensors through the integration of NPs into biocatalytic reactions. Development of nanobiotechnology has been rapid with the introduction of biocatalysts on metal nanoparticles (MNPs) [3].

In recent times, neodymium oxide nanoparticles $\left(\mathrm{Nd}^{+}\right.$ NPs) had been in the application of optical and magnetic nanomaterials due to their unique optical properties [5]. Like other lanthanides, $\mathrm{Nd}$ has a contracted nature of the 4 f orbitals shielded by the $5 \mathrm{~s}$ and $5 \mathrm{p}$ shells that affect their physical properties. Below $10 \mathrm{~nm}$ particle size, the quantum properties of neodymium compounds are size dependent and exhibit a secondary morphology that is well defined. Such property of $\mathrm{Nd}$ compounds makes them suitable for applications in surface catalytic systems, photonics, and advanced NP-based materials and protective coatings $[5,6]$.

Neodymium doped tellurite glasses are suitable candidates for the development of optical fibers and optical amplifiers, waveguide lasers, and color display devices [7-9]. 
The study of the elastic properties of glasses by using the nondestructive ultrasonic technique gives some details about the structure of the studied glasses and can be directly connected to the interatomic potentials of the glasses under probe $[10$, 11]. The study of the elastic properties is of fundamental importance in studying the nature of interatomic bonding and the mechanical properties of materials [12-14].

However, there is no information on elastic properties of neodymium nanoparticles doped zinc-tellurite glass. Therefore, this research is focused on the determination of the elastic properties of neodymium NPs doped zinc-tellurite glass. This is important as it will help the continued research on both scientific and technological applications of the $\mathrm{Nd}$ nanoparticles/compounds.

\section{Experimental Section}

The glass samples of $\mathrm{Nd}^{3+}$ doped zinctellurite glass system with chemical formula $\left[\left(\mathrm{TeO}_{2}\right)_{0.70}(\mathrm{ZnO})_{0.30}\right]_{(1-x)}\left(\mathrm{Nd}_{2} \mathrm{O}_{3} \mathrm{NPs}\right)_{(x)}, x=0.01,0.02$, $0.03,0.04$, and $0.05 \mathrm{~mol}$, were prepared by using a conventional method of melt quenching. High purity raw materials (99.99\%, purity grade) of $\mathrm{TeO}_{2}$ (Puratronic, Alfa Aesar), $\mathrm{ZnO}$ (Assay, Alfa Aesar), and $\mathrm{Nd}_{2} \mathrm{O}_{3}$ nanoparticles (Assay, Alfa Aesar) were used to prepare the glass samples. The oxide components used in preparing the glasses were weighed by using a high accuracy $( \pm 0.0001 \mathrm{~g})$ digital weighing machine and mixed together in an alumina crucible. The mixture was put in a furnace for 1 hour at $400^{\circ} \mathrm{C}$ to allow complete drying of the mixture. After heating, the mixture was transferred to a second furnace at $830^{\circ} \mathrm{C}$ for 90 minutes for the melting process [2]. Then, the molten sample was immediately poured into a stainless steel mould and annealed at $400^{\circ} \mathrm{C}$ in an electrical furnace before cooling down to room temperature [14]. All the prepared samples were cut into the required dimension, and the sample thickness (4-6 mm) was measured using a digital Vernier caliper with an accuracy of $0.0001 \mathrm{~mm}$, and the samples were then polished using sandpaper to obtain parallel surfaces on both sides. The excessive glass samples were crushed into a powder form for structural analysis. Structural analysis of the prepared samples was studied using $\mathrm{X}$-ray diffraction (XRD) and the FTIR analysis. The density, $\rho$, of the glasses was measured using electronic densimeter MD-300S based on Archimedes' principle and the molar volume, $V_{m}$, was calculated. The longitudinal and shear velocities for the samples were measured using the ultrasonic pulse-echo technique by Ritec Ram-5000 Snap System. All ultrasonic measurements were taken at $5 \mathrm{MHz}$ frequency and at room temperature.

2.1. Elastic Modulus. Elastic moduli (longitudinal, shear, bulk, and Young's) of $\left[\left(\mathrm{TeO}_{2}\right)_{0.70}(\mathrm{ZnO})_{0.30}\right]_{(1-x)} \mathrm{Nd}_{2} \mathrm{O}_{3(x)}$ glasses were calculated from the measured ultrasonic velocities and density using the following standard relations:

Longitudinal modulus is expressed as

$$
L=v_{l}^{2} \rho
$$

Shear modulus is expressed as

$$
G=v_{s}^{2} \rho \text {. }
$$

Bulk modulus is expressed as

$$
K=L-\left(\frac{4}{3}\right) G \text {. }
$$

Young's modulus is expressed as

$$
E=(1+\sigma) 2 G
$$

Poisson's Ratio. Poisson's ratio gives the description of the sample's expansion in a direction that is perpendicular to the applied stress [16]. It is expressed mathematically as

$$
\sigma=\left(\frac{(L-2 G)}{2(L-G)}\right) .
$$

Microhardness is expressed as

$$
H=\frac{(1-2 \sigma) E}{6(1+\sigma)},
$$

where $v_{l}$ and $v_{s}$ are ultrasonic longitudinal and shear velocities, respectively, and $\rho$ is the sample density $[10,17,18]$.

Softening temperature is expressed as

$$
T_{s}=\left(\frac{M v_{s}^{2}}{C^{2} n}\right)
$$

where $M$ is the molecular weight of the glass, $C$ is constantly equal to $507.4 \mathrm{~ms}^{-1} \mathrm{~K}^{-1 / 2}$, and $n$ is the number of atoms in the chemical formula $[10,17]$.

Debye temperature is expressed as

$$
\theta_{D}=\frac{h}{k}\left(\frac{3 n N_{A}}{4 \pi V_{m}}\right)^{1 / 3} U_{m} .
$$

Mean ultrasonic velocity is expressed as

$$
U_{m}=\left[\frac{1}{3}\left(\frac{1}{v_{l}^{3}}+\frac{2}{v_{s}^{3}}\right)\right]^{-1 / 3},
$$

where $h$ is Plank's constant, $k$ is the Boltzmann constant, $U_{m}$ is the mean ultrasonic velocity, $N_{A}$ is Avogadro's number, and $V_{m}$ is the molar volume $[17,19]$.

\section{Results and Discussion}

The XRD spectra of $\left[\left(\mathrm{TeO}_{2}\right)_{0.70}(\mathrm{ZnO})_{0.30}\right]_{(1-x)}\left(\mathrm{Nd}_{2} \mathrm{O}_{3}\right.$ $\mathrm{NPs})_{(x)}$ are shown in Figure 1. The XRD pattern of the glass shows a broad hump at $20-35^{\circ}$ for $2 \theta$ values without any distinguishable sharp peaks. Such kind of spectra indicates the characteristics of amorphous structures. There are absent sharp peaks from the XRD spectra which in turn confirms the nonexistence of a crystalline phase. This result is consistent with the previous work of many authors $[20,21]$. 


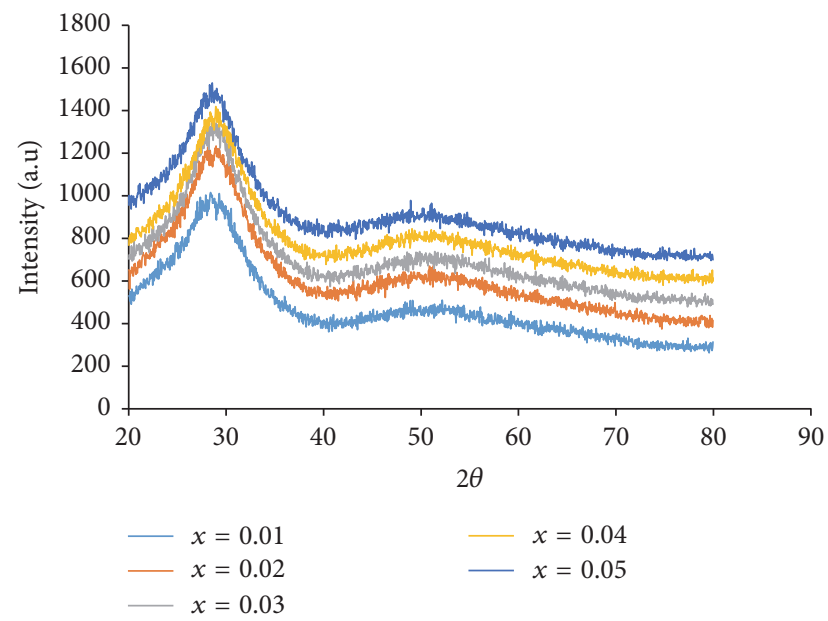

FIGURE 1: XRD spectra of $\left[\left(\mathrm{TeO}_{2}\right)_{0.70}(\mathrm{ZnO})_{0.30}\right]_{(1-x)}\left(\mathrm{Nd}_{2} \mathrm{O}_{3} \mathrm{NPs}\right)_{(x)}$ glasses.

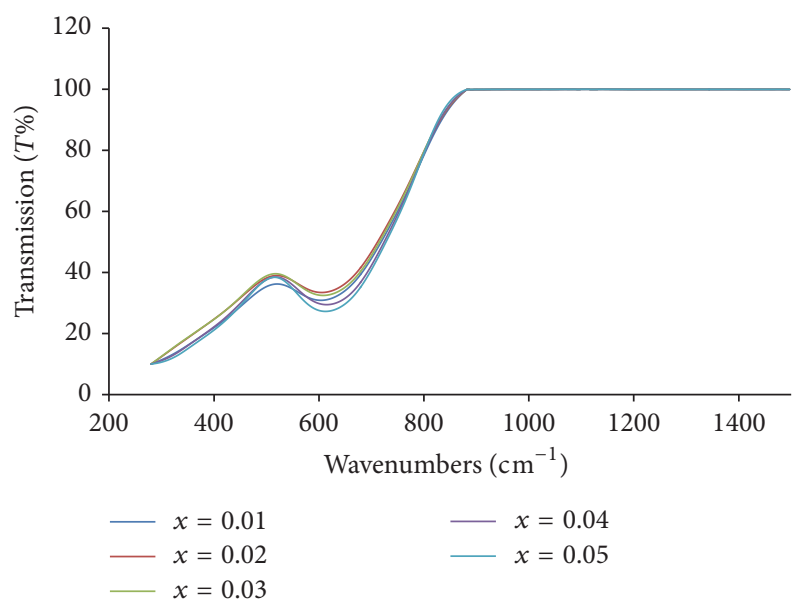

FIGURE 2: FTIR spectra of $\left[\left(\mathrm{TeO}_{2}\right)_{0.70}(\mathrm{ZnO})_{0.30}\right]_{(1-x)}\left(\mathrm{Nd}_{2} \mathrm{O}_{3} \mathrm{NPs}\right)_{(x)}$ glasses.

3.1. Fourier Transform Analysis. The Fourier transform infrared (FTIR) spectrometry is an analysis technique that provides structural studies to explore the basic and functional groups in crystalline and noncrystalline matrices. The result of FTIR shows the characteristics of chemical bonds that exist between elements. Absorption peaks in the spectrum represent the frequencies of vibrations between the bonds of the atom or molecule [8]. Tellurite oxide is characterized by two major structural configuration units: trigonal bipyramid $\left(\mathrm{TeO}_{4}\right)$ and trigonal pyramid $\left(\mathrm{TeO}_{3}\right)$. Pure $\mathrm{TeO}_{2}$ is characterized by infrared absorption at around $640 \mathrm{~cm}^{-1}$. The absorption band at $600-700 \mathrm{~cm}^{-1}$ represents the stretching vibration of Te-O bonds in the trigonal bipyramid $\left(\mathrm{TeO}_{4}\right)$ and trigonal pyramid $\left(\mathrm{TeO}_{3}\right)$. The stretching vibration of $\mathrm{TeO}_{3}$ group is between 650 and $700 \mathrm{~cm}^{-1}$ while the stretching vibration of $\mathrm{TeO}_{4}$ is between 600 and $650 \mathrm{~cm}^{-1}$ [22].

Figure 2 shows the FTIR spectra that had been obtained within the region $250-1300 \mathrm{~cm}^{-1}$ of wavenumber. The spectra contain a valley which indicates the type of bonding present.

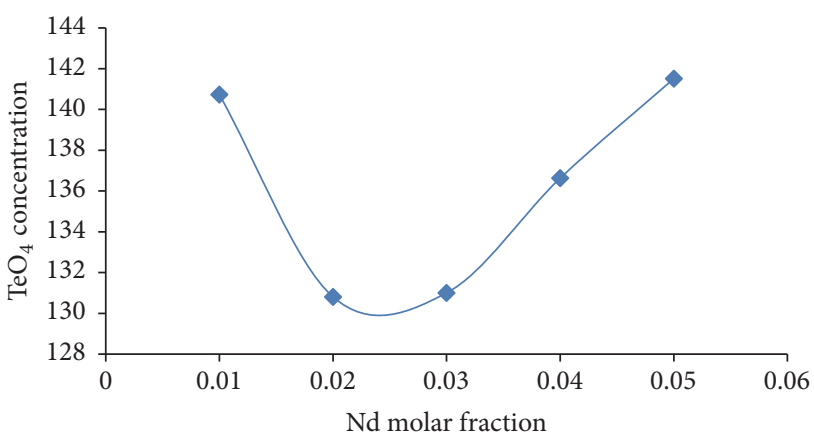

Figure 3: $\mathrm{TeO}_{4}$ concentration of $\left[\left(\mathrm{TeO}_{2}\right)_{0.70}(\mathrm{ZnO})_{0.30}\right]_{(1-x)}\left(\mathrm{Nd}_{2} \mathrm{O}_{3}\right.$ $\mathrm{NPs})_{(x)}$ glasses.

The IR characteristic of the two tellurium oxide structural units is observed in the range of $600-700 \mathrm{~cm}^{-1}$. It was reported that, after glass formation, tellurium oxide is formed in two structural units, namely, trigonal pyramid $\left(\mathrm{TeO}_{3}\right)$ and trigonal pyramid $\left(\mathrm{TeO}_{4}\right)$. The primary cluster of the band is observed within the range $604.48-614.22 \mathrm{~cm}^{-1}$ that correlates to the symmetrical pyramid, $\mathrm{TeO}_{4}$ structural unit. This result is in agreement with the previous work done by Hajer et al. (2016) [15].

The presence of $\mathrm{ZnO}$ band does not show in the spectra, indicating that the zinc lattice is completely broken down. The formation of $\mathrm{TeO}_{4}$ in the glass samples leads to the tight binding of oxygen anions in the glass network. Hence, increasing the $\mathrm{TeO}_{4}$ concentration leads to a decrease in the amount of nonbridging oxygen, whereas the decrease in the concentration of $\mathrm{TeO}_{4}$ leads to the increase in the amount of nonbridging oxygen $[15,21]$.

Using the FTIR spectra, the concentration of $\mathrm{TeO}_{4}$ in each of the glass samples was calculated. In order to calculate the concentration of $\mathrm{TeO}_{4}$, the transmission spectra were changed to absorption spectra. The area under the $\mathrm{TeO}_{4}$ absorption curve then represents the concentration of the $\mathrm{TeO}_{4}$ in the glass. To calculate the concentration, Origin 6.0 software was used to obtain the area under the absorption curve. The absorption value is calculated and plotted against the wavenumber, and the software can be used to calculate the area under each Gaussian absorption curve for each of the functional groups present. The area, therefore, is considered as the concentration of $\mathrm{TeO}_{4}$ in the glass. Table 1 and Figure 3 present the variation of $\mathrm{TeO}_{4}$ concentration against the $\mathrm{Nd}$ moles.

In this experiment, it was observed that the concentration of $\mathrm{TeO}_{4}$ decreased as the concentration of $\mathrm{Nd}^{3+}$ ions increased from 0.01 to $0.02 \mathrm{~mol}$, indicating an increasing amount of nonbridging oxygen. On the other hand, as the concentration of $\mathrm{Nd}^{3+}$ ions increases from 0.02 to $0.05 \mathrm{~mol}$, the $\mathrm{TeO}_{4}$ concentration was seen to increase steadily. The $\mathrm{TeO}_{4}$ concentration increase indicates the closely packed network due to the formation of more bridging oxygen (BO) [23]. This trend is supported by the formation of trigonal pyramidal $\mathrm{TeO}_{3}$ structural units within the glass system and results in a change of structural units from $\mathrm{TeO}_{3}$ to $\mathrm{TeO}_{4}$ with the formation of bridging oxygen [22]. 
TABLE 1: Assignment of infrared transmission bands of the prepared glass sample with different concentrations of lanthanum neodymium oxide nanoparticles.

\begin{tabular}{lcccccc}
\hline Number & 0.01 & 0.02 & 0.03 & 0.04 & 0.05 & Assignments \\
\hline$(1)$ & 604.48 & 605.92 & 609.08 & 614.22 & 612.59 & $\mathrm{TeO}_{4}$ group exists in all tellurite containing glasses [15] \\
$(2)$ & 140.73 & 130.81 & 131 & 136.63 & 141.51 & Area (TeO $_{4}$ concentration) \\
$(3)$ & - & - & - & - & - & ZnO participates in the glass network $^{2}$ \\
\hline
\end{tabular}

TABle 2: Density and molar volume of $\left[\left(\mathrm{TeO}_{2}\right)_{0.70}(\mathrm{ZnO})_{0.30}\right]_{(1-x)}\left(\mathrm{Nd}_{2} \mathrm{O}_{3} \mathrm{NPs}\right)_{(x)}$ glasses.

\begin{tabular}{lcc}
\hline$X$ & $\rho\left( \pm 40 \mathrm{~kg} / \mathrm{m}^{3}\right)$ & $V_{m}\left( \pm 0.00722 \times 10^{-5} \mathrm{~m}^{3} / \mathrm{mol}\right)$ \\
\hline 0.01 & 5390 & 2.5628 \\
0.02 & 5437 & 2.5775 \\
0.03 & 5507 & 2.5811 \\
0.04 & 5570 & 2.5879 \\
0.05 & 5606 & 2.6070 \\
\hline
\end{tabular}

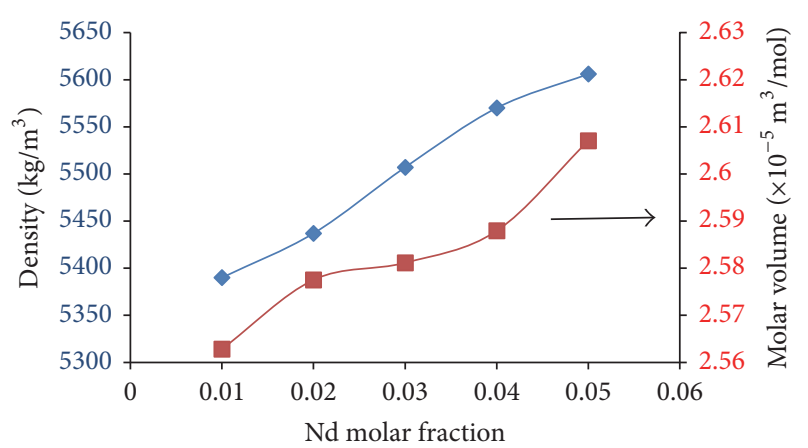

$$
\begin{aligned}
& \multimap \text { Density } \\
& \rightarrow-\text { Molar volume }
\end{aligned}
$$

FIGURE 4: Density and molar volume of $\left[\left(\mathrm{TeO}_{2}\right)_{0.70}(\mathrm{ZnO})_{0.30}\right]_{(1-x)}\left(\mathrm{Nd}_{2} \mathrm{O}_{3} \mathrm{NPs}\right)_{(x)}$ glasses.

3.2. Density and Molar Volume. The values of density and molar volume of $\left[\left(\mathrm{TeO}_{2}\right)_{0.70}(\mathrm{ZnO})_{0.30}\right]_{(1-x)}\left(\mathrm{Nd}_{2} \mathrm{O}_{3} \mathrm{NPs}\right)_{(x)}$ glasses are tabulated in Table 2. Figure 4 shows the variation of density and molar volume. The density of the prepared glasses increased from $5346 \mathrm{~kg} / \mathrm{m}^{3}$ to $5580 \mathrm{~kg} / \mathrm{m}^{3}$ as the concentration of $\mathrm{Nd}_{2} \mathrm{O}_{3}$ increased from 0.01 to $0.05 \mathrm{~mol} \%$. The increase in density of the prepared glass is due to the substitution of lighter atoms of $\mathrm{ZnO}$ with heavier atoms of $\mathrm{Nd}_{2} \mathrm{O}_{3}$ which in turn increases the overall average molecular weight of the glass $[18,24]$.

The molar volume $\left(V_{m}\right)$ is defined as the volume occupied by one mol of a material and has been calculated as

$$
V_{m}=\frac{M_{w}}{\rho},
$$

where $M_{w}$ is the molecular weight of the glass sample and $\rho$ is the density of glass [25].

The molar volume shows increasing values from $25.464 \mathrm{~cm}^{3} / \mathrm{mol}$ to $26.192 \mathrm{~cm}^{3} / \mathrm{mol}$ as the concentration of $\mathrm{Nd}_{2} \mathrm{O}_{3}$ NPs increases from 0.01 to $0.05 \mathrm{~mol} \%$.

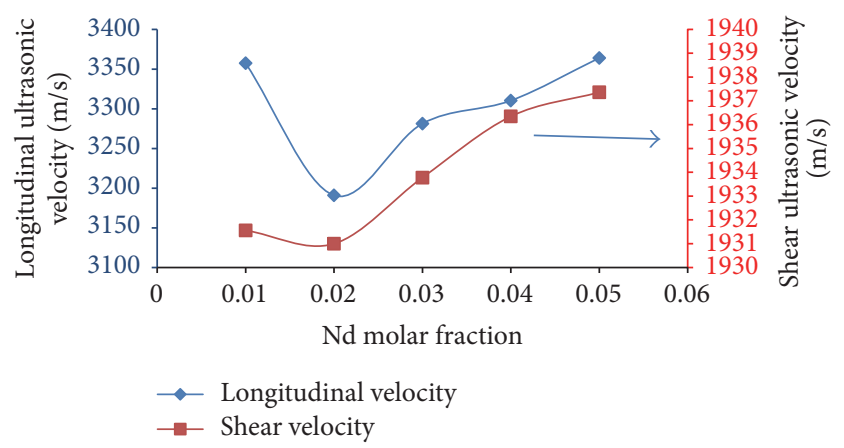

FIgURE 5: Ultrasonic velocities of $\left[\left(\mathrm{TeO}_{2}\right)_{0.70}(\mathrm{ZnO})_{0.30}\right]_{(1-x)}\left(\mathrm{Nd}_{2} \mathrm{O}_{3}\right.$ $\mathrm{NPs})_{(x)}$ glasses

The increasing in the molar volume with the increase in $\mathrm{Nd}_{2} \mathrm{O}_{3}$ concentration (Table 2) is attributed to the increase in the amount of nonbridging oxygen (NBO). The neodymium oxide in the glass network acts as a modifier by occupying the interstitial space in the network and creating more NBO in the structure. Thus, the addition of $\mathrm{Nd}_{2} \mathrm{O}_{3} \mathrm{NPs}$ may eventually result in an extension of the glass network [26]. After $x=0.02$, the increase in the molar volume may be due to the substitution of smaller atoms of Te and $\mathrm{Zn}$ in the network with larger atoms of $\mathrm{Nd}$. In the present work, it is shown that the molar volume of the glasses increases with an increase in $\mathrm{Nd}_{2} \mathrm{O}_{3}$ NPs concentration. Hence, the increase in molar volume indicates the increasing of free volume in the glass network. This result is consistent with previous work done by Chimalawong et al. (2010) and Zaid et al. (2012) [26, 27].

3.3. Elastic Properties. The variations of shear and longitudinal ultrasonic velocities of $\left[\left(\mathrm{TeO}_{2}\right)_{0.70}(\mathrm{ZnO})_{0.30}\right]_{(1-x)}-\mathrm{Nd}_{2} \mathrm{O}_{3}$ $\mathrm{NPs}_{(x)}$ glasses at room temperature are listed in Table 3 and shown in Figure 5. The measured values of the longitudinal and shear ultrasonic velocities ( $v_{L}$ and $v_{s}$, resp.) for the studied (NdNPsZT) glass system with a variation of $\mathrm{Nd}_{2} \mathrm{O}_{3}$ content are listed in Table 3 . The longitudinal and shear ultrasonic velocities decreased from 3737 to $3045 \mathrm{~ms}^{-1}$ and 1959.3 to $1887.8 \mathrm{~ms}^{-1}$, respectively, as the amount of $\mathrm{Nd}^{3+} \mathrm{NPs}$ ions increased from 0.01 to $0.02 \mathrm{~mol}$. The decrease in the ultrasonic velocities may be due to the decrease in the connectivity in the glass network caused by the increase in nonbridging oxygen (NBOs) [17].

However, as more $\mathrm{Nd}^{3+}$ ions are introduced into this glass network from 0.02 to $0.05 \mathrm{~mol}$, the ultrasonic velocities increase. This may be due to an increase in the particle compactness as a result of an increase in the amount of bridging oxygen as $\mathrm{TeO}_{4}$ increases [28]. 
TABLE 3: Ultrasonic velocities (longitudinal, shear, Young's, and bulk modulus) and fractal bond connectivity of $\left[\left(\mathrm{TeO}_{2}\right)_{0.70}(\mathrm{ZnO})_{0.30}\right]_{(1-x)}\left(\mathrm{Nd}_{2} \mathrm{O}_{3} \mathrm{NPs}\right)_{(x)}$ glasses.

\begin{tabular}{lccccccc}
\hline$X$ & $v_{L}(\mathrm{~m} / \mathrm{s})$ & $v_{s}(\mathrm{~m} / \mathrm{s})$ & $L(\mathrm{GPa})$ & $G(\mathrm{GPa})$ & $E(\mathrm{GPa})$ & $K(\mathrm{GPa})$ & $d=4 \frac{G}{K}$ \\
\hline 0.01 & 3357.464 & 1931.559 & 60.7591 & 20.1097 & 50.3805 & 33.9462 \\
0.02 & 3190.886 & 1931.000 & 55.3582 & 20.2733 & 49.1052 & 28.3272 \\
0.03 & 3281.337 & 1933.777 & 59.295 & 20.5934 & 50.8222 & 31.8369 & 2.8695 \\
0.04 & 3310.329 & 1936.346 & 61.0376 & 20.8844 & 51.7908 & 33.1918 \\
0.05 & 3364.002 & 1937.360 & 63.4404 & 21.0414 & 52.6819 & 35.3852 & 2.5168 \\
\hline
\end{tabular}

TABle 4: Poisson's ratio, microhardness, Debye temperature, and softening temperature of $\left[\left(\mathrm{TeO}_{2}\right)_{0.70}(\mathrm{ZnO})_{0.30}\right]_{(1-x)}\left(\mathrm{Nd}_{2} \mathrm{O}_{3} \mathrm{NPs}\right)_{(x)}$ glasses.

\begin{tabular}{lcccc}
\hline$X$ & $\sigma$ & $H(\mathrm{GPa})$ & $\theta_{D}(\mathrm{k})$ & $T_{s}(\mathrm{k})$ \\
\hline 0.01 & 0.2526 & 3.3161 & 255.4863 & 735.1503 \\
0.02 & 0.2111 & 3.9048 & 254.5954 & 739.1378 \\
0.03 & 0.2339 & 3.6526 & 256.1572 & 745.6174 \\
0.04 & 0.2399 & 3.6207 & 257.1575 & 751.8914 \\
0.05 & 0.2519 & 3.4807 & 257.7215 & 756.9057 \\
\hline
\end{tabular}

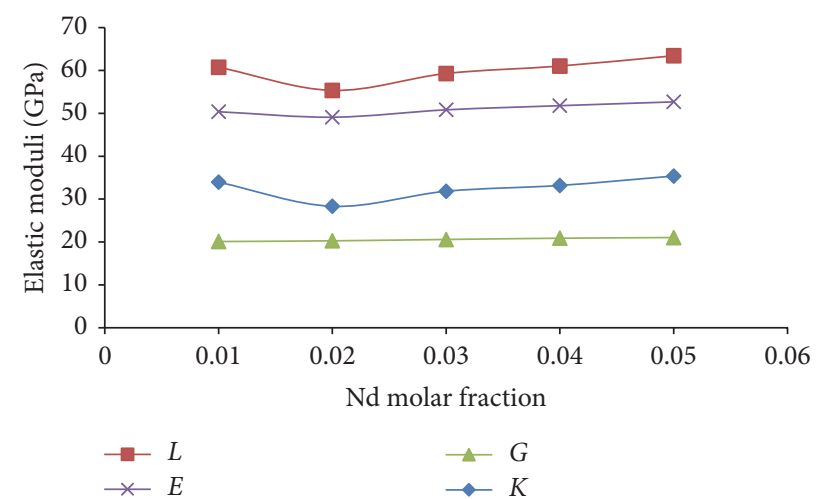

Figure 6: Elastic moduli of $\left[\left(\mathrm{TeO}_{2}\right)_{0.70}(\mathrm{ZnO})_{0.30}\right]_{(1-x)}\left(\mathrm{Nd}_{2} \mathrm{O}_{3}\right.$ $\mathrm{NPs})_{(x)}$ glasses.

The elastic moduli $(L, G, K$, and $E$ ) are presented in Table 3 and are shown in Figure 6. It is shown that the elastic moduli decreased with the increase in $\mathrm{Nd}^{3+}$ NPs concentrations from 0.01 to $0.02 \mathrm{~mol}$. The elastic moduli of glass are related to the number of bonds per unit volume of the glass samples. The decrease observed in elastic moduli is related to the increase of nonbridging oxygen (NBO) and consequently increased glass network connectivity [29].

Also, like the ultrasonic velocity, the elastic moduli showed the same trend that is increasing with an increment of $\mathrm{Nd}^{3+} \mathrm{NPs} 0.02$ to $0.05 \mathrm{~mol}$ content. The increase in the elastic moduli of the prepared glasses can be attributed to the change in the structural unit due to the formation of more $\mathrm{TeO}_{4}$ which in turn leads to the formation of more bridging oxygen (BO) atoms [18]. This increased the rigidity of the glass and consequently increased the elastic moduli of the glass samples $[18,30]$.

Figure 7 shows the variation of fractal bond connectivity (d). This parameter tells about the effective dimensionality of the glass network. From the obtained result, it increased with Nd NPs concentration from 0.01 to $0.02 \mathrm{~mol}$ and decreased with Nd NPs concentration from 0.02 to 0.05 mol. The initial increase may be due to the increase in the amount of nonbridging oxygen which in turn decreases glass connectivity. The increase in the value may be associated with the increasing amount of bridging oxygen which causes an increase in the glass network connectivity [31].

Poisson's ratio is shown in Table 4, and Figure 8 shows a decrease in Poisson's ratio from 0.01 to $0.02 \mathrm{~mol}$ and increase from 0.02 to $0.05 \mathrm{~mol}$ as Nd NPs increase. The initial decrease may be associated with a decrease in the rigidity in the glass network. The increase in the Poisson ratio value recorded beyond $0.02 \mathrm{~mol}$ may be attributed to increasing rigidity in the glass network due to increasing connectivity [29].

The microhardness is the amount of stress required to remove the free volume of glass [32]. It is associated with the glass rigidity as it increases as the glass gets less rigid and decreases with increasing rigidity. Hence, the trend in Figure 9 shows an initial increase in the value with the increase in Nd ion concentration from 0.01 to $0.02 \mathrm{~mol}$ and may be due to decreasing rigidity. The observed decrease in the values of microhardness $(\mathrm{H})$ with $\mathrm{Nd}$ ion concentration from 0.02 up to 0.05 can be said to be due to increasing rigidity [29]. The rigidity increase is due to increasing connectivity [33].

The variations of Debye and the softening temperatures with $\mathrm{Nd}_{2} \mathrm{O}_{3}$ concentration are presented in Table 4 and Figure 10. Debye temperature represents the temperature at which almost all the vibration modes in the glass are at excited states. The observed decrease in the value may be due to the increase in the rigidity as a result of the amount of nonbridging oxygen increase and Debye temperature also decreases with a decrease in the ultrasonic velocities. The increase observed from 0.02 to $0.05 \mathrm{~mol}$ of Nd NPs ions is attributed to the increasing rigidity and connectivity [34].

The observed value of the softening temperature as shown in both Table 4 and Figure 10 may be attributed to the increase 


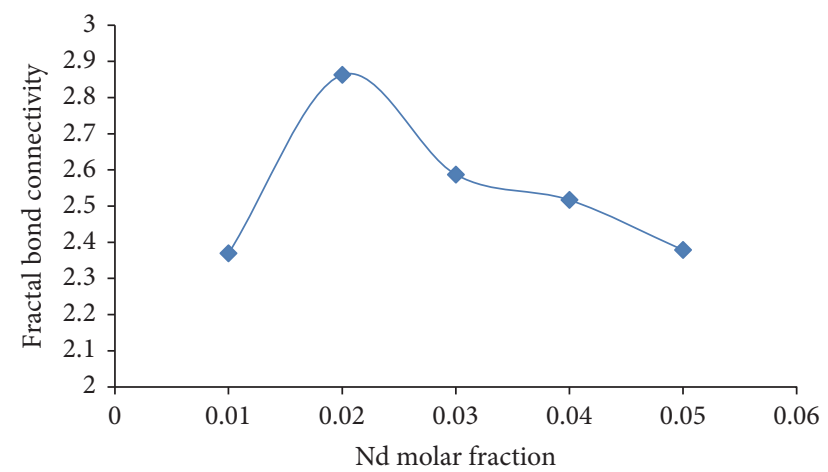

Figure 7: Fractal bond connectivity of $\left[\left(\mathrm{TeO}_{2}\right)_{0.70}(\mathrm{ZnO})_{0.30}\right]_{(1-x)}\left(\mathrm{Nd}_{2} \mathrm{O}_{3} \mathrm{NPs}\right)_{(x)}$ glasses.

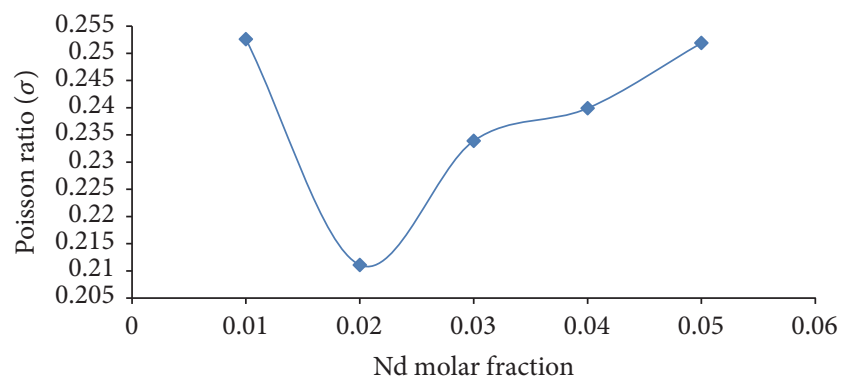

Figure 8: Poisson's ratio of $\left[\left(\mathrm{TeO}_{2}\right)_{0.70}(\mathrm{ZnO})_{0.30}\right]_{(1-x)}\left(\mathrm{Nd}_{2} \mathrm{O}_{3}\right.$ $\mathrm{NPs})_{(x)}$ glasses.

in the connectivity in the glass and increase in the degree of compactness [29].

\section{Conclusion}

A series of neodymium nanoparticles doped zinc-tellurite glass systems of composition $\left[\left(\mathrm{TeO}_{2}\right)_{0.70}(\mathrm{ZnO})_{0.30}\right]_{(1-x)} \mathrm{Nd}_{2} \mathrm{O}_{3(x)}, x=0.01,0.02,0.03,0.04$, and $0.05 \mathrm{~mol}$, have been successfully prepared. The structural characteristics of neodymium nanoparticles doped zinc-tellurite glasses were studied thoroughly. XRD patterns showed that the present glasses were amorphous in nature. The density of neodymium nanoparticles doped zinc-tellurite glasses increased as $\mathrm{Nd}_{2} \mathrm{O}_{3}$ NPs content increased while molar volume showed both decreasing and increasing values. The changes in density and molar volume are due to the high molecular weight of $\mathrm{Nd}_{2} \mathrm{O}_{3}$ NPs and structural change in the glass network. It is observed that the ultrasonic velocities and elastic moduli decreased from 0.01 to 0.02 molar concentrations of Nd NPs ions and later increased from 0.02 to 0.05 molar concentrations. This decrease and the later increase are due to the increase in the amount of nonbridging oxygen in the beginning and bridging oxygen after 0.02 molar Nd NPs. The increase in the nonbridging oxygen leads to the decrease in rigidity while the increase in bridging oxygen increases its rigidity. The microhardness was found to decrease after 0.02 which can be attributed to the increase in glass rigidity and compactness. The observed

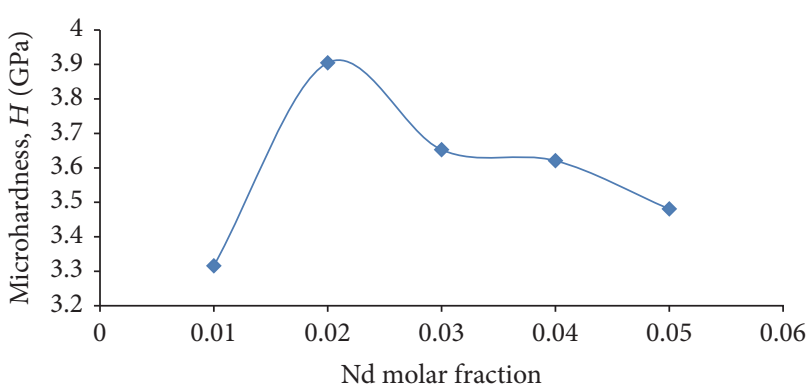

Figure 9: Microhardness of $\left[\left(\mathrm{TeO}_{2}\right)_{0.70}(\mathrm{ZnO})_{0.30}\right]_{(1-x)}\left(\mathrm{Nd}_{2} \mathrm{O}_{3}\right.$ $\mathrm{NPs})_{(x)}$ glasses.

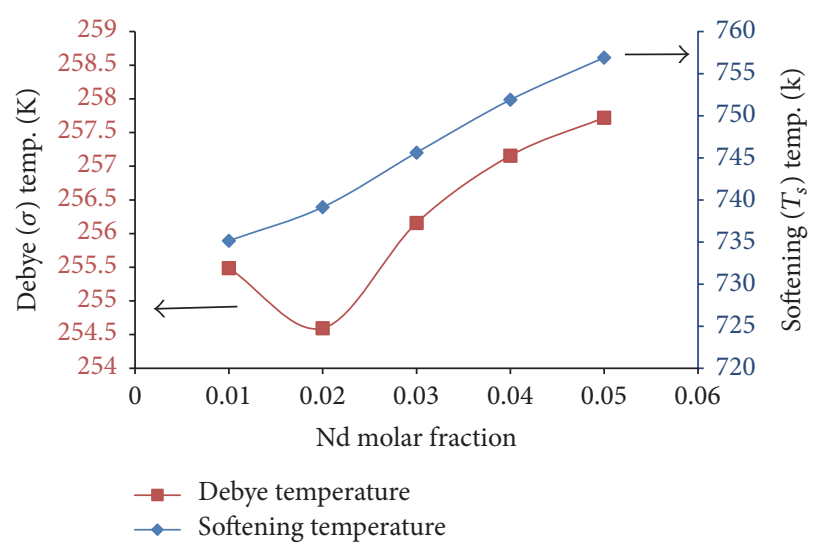

FIgUre 10: Debye and softening temperature of $\left[\left(\mathrm{TeO}_{2}\right)_{0.70}(\mathrm{ZnO})_{0.30}\right]_{(1-x)}\left(\mathrm{Nd}_{2} \mathrm{O}_{3} \mathrm{NPs}\right)_{(x)}$ glasses.

variation of Poisson's ratio, Debye temperature, and softening temperature was attributed to the change in the rigidity and connectivity in the glass system caused by the introduction of high $\mathrm{Nd}^{3+} \mathrm{NPs}$ ions in the glass network.

\section{Conflicts of Interest}

The authors declare that they have no conflicts of interest.

\section{Acknowledgments}

The authors would like to appreciate the financial support from the Ministry of Higher Education of Malaysia and Universiti Putra Malaysia through FRGS (5524817).

\section{References}

[1] M. S. Gaafar, I. Shaarany, and T. Alharbi, "Structural investigations on some cadmium-borotellurate glasses using ultrasonic, FT-IR and X-ray techniques," Journal of Alloys and Compounds, vol. 616, pp. 625-632, 2014.

[2] A. M. Noorazlan, H. M. Kamari, S. O. Baki, and D. W. Mohamad, "Green emission of tellurite based glass containing erbium oxide nanoparticles," Journal of Nanomaterials, vol. 2015, Article ID 952308, 9 pages, 2015.

[3] Q. Sheng, Y. Shen, H. Zhang, and J. Zheng, "Neodymium (III) hexacyanoferrate (II) nanoparticles induced by enzymatic 
reaction and their use in biosensing of glucose," Electrochimica Acta, vol. 53, no. 14, pp. 4687-4692, 2008.

[4] A. Dorris, C. Sicard, M. C. Chen, A. B. McDonald, and C. J. Barrett, "Stabilization of neodymium oxide nanoparticles via soft adsorption of charged polymers," ACS Applied Materials and Interfaces, vol. 3, no. 9, pp. 3357-3365, 2011.

[5] V. Ter-Mikirtychev, "Fundamentals of fiber lasers and fiber amplifiers," Springer Series in Optical Sciences, vol. 181, pp. 1-253, 2014.

[6] B. Bhatia, S. L. Meena, V. Parihar, and M. Poonia, "Optical Basicity and Polarizability of $\mathrm{Nd}^{3+}$-Doped Bismuth Borate Glasses," New Journal of Glass and Ceramics, vol. 5, no. 3, pp. 44-52, 2015.

[7] M. J. V. Bell, V. Anjos, L. M. Moreira et al., "Laser emission of a Nd-doped mixed tellurite and zinc oxide glass," Journal of the Optical Society of America B: Optical Physics, vol. 31, no. 7, pp. 1590-1594, 2014.

[8] M. N. Azlan, M. K. Halimah, S. O. Baki, and W. M. Daud, "Effect of neodymium concentration on structural and optical properties of tellurite based glass system," Materials Science Forum, vol. 846, pp. 183-188, 2016.

[9] N. A. M. Jan, "Thermal and Photoluminescence Properties of $\mathrm{Nd}^{3+}$ Doped Tellurite Nanoglass," International Journal Nanoelectronics, vol. 7, pp. 9-16, 2014.

[10] M. K. Halimah, W. M. Daud, and H. A. A. Sidek, "Elastic properties of $\mathrm{TeO}_{2}-\mathrm{B}_{2} \mathrm{O}_{3}-\mathrm{Ag}_{2} \mathrm{O}$ glasses," Ionics, vol. 16, no. 9, pp. 807-813, 2010.

[11] R. E. Pavai and M. Indhira, "Study of elastic properties of potassium borate glasses doped with barium oxide," International Journal Of Innovative Research In Science, Engineering and Technology, pp. 7244-7252, 2015.

[12] G. E. El-Falaky, M. S. Gaafar, and N. S. A. El-Aal, "Ultrasonic relaxation in Zinc-Borate glasses," Current Applied Physics, vol. 12, no. 2, pp. 589-596, 2012.

[13] S. Thirumaran and K. Sathish, "Spectroscopic investigations on structural characterization of borate glass specimen doped with transition metal ions," Research Journal of Chemistry and Environment, vol. 18, no. 10, pp. 77-82, 2014.

[14] A. Azuraida, M. K. Halimah, A. A. Sidek et al., "Comparative studies of bismuth and barium boro-tellurite glass system: Structural and optical properties," Chalcogenide Letters, vol. 12, no. 10, pp. 497-503, 2015.

[15] S. S. Hajer, M. K. Halimah, Z. Azmi, and M. N. Azlan, "Effect of samarium nanoparticles on optical properties of zinc borotellurite glass system," Materials Science Forum, vol. 846, pp. 6368, 2016.

[16] E. S. Yousef, M. M. Elokr, and Y. M. Aboudeif, "Optical, elastic properties and DTA of TNZP host tellurite glasses doped with Er3+ ions," Journal of Molecular Structure, vol. 1108, pp. 257-262, 2016.

[17] C. Bootjomchai, "Comparative studies between theoretical and experimental of elastic properties and irradiation effects of soda lime glasses doped with neodymium oxide," Radiation Physics and Chemistry, vol. 110, pp. 96-104, 2015.

[18] C. Eevon, M. K. Halimah, Z. Azmi, and C. Azurahanim, "Elastic properties of $\mathrm{TeO} 2-\mathrm{B} 2 \mathrm{O} 3-\mathrm{ZnO}-\mathrm{Gd} 2 \mathrm{O} 3$ glasses using nondestructive ultrasonic technique," Chalcogenide Letters, vol. 13, no. 6, pp. 281-289, 2016.

[19] N. B. Mohamed, A. K. Yahya, M. S. M. Deni, S. N. Mohamed, M. K. Halimah, and H. A. A. Sidek, "Effects of concurrent $\mathrm{TeO} 2$ reduction and $\mathrm{ZnO}$ addition on elastic and structural properties of (90-x)TeO2-10Nb2O 5-(x)ZnO glass," Journal of Non-Crystalline Solids, vol. 356, no. 33-34, pp. 1626-1630, 2010.

[20] H. Fares, I. Jlassi, S. Hraiech, H. Elhouichet, and M. Férid, "Radiative parameters of $\mathrm{Nd} 3+$-doped titanium and tungsten modified tellurite glasses for $1.06 \mu \mathrm{m}$ laser materials," Journal of Quantitative Spectroscopy and Radiative Transfer, vol. 147, pp. 224-232, 2014.

[21] H. Mohamed-Kamari, H. M. Oo, and W. M. D. Wan-Yusoff, "Optical properties of bismuth tellurite based glass," International Journal of Molecular Sciences, vol. 13, no. 4, pp. 4623-4631, 2012.

[22] S. S. Hajer, M. K. Halimah, Z. Azmi, and M. N. Azlan, "Optical properties of zinc-borotellurite doped samarium," Chalcogenide Letters, vol. 11, no. 11, pp. 553-566, 2014.

[23] H. A. A. S. M. N. Azlan, M. K. Halimah, S. Z. Shafinas, and W. M. Daud, "Physics, Influence Of Erbium Concentration On Spectroscopic Properties Of Tellurite Based Glass," Solid State Science And Technology, vol. 22, pp. 148-156, 2014.

[24] P. Gayathri Pavani, K. Sadhana, and V. Chandra Mouli, "Optical, physical and structural studies of boro-zinc tellurite glasses," Physica B: Condensed Matter, vol. 406, no. 6-7, pp. 1242-1247, 2011.

[25] M. S. Gaafar, N. S. A. El-Aal, O. W. Gerges, and G. El-Amir, "Elastic properties and structural studies on some zinc-borate glasses derived from ultrasonic, FT-IR and X-ray techniques," Journal of Alloys and Compounds, vol. 475, no. 1-2, pp. 535-542, 2009.

[26] P. Chimalawong, J. Kaewkhao, C. Kedkaew, and P. Limsuwan, "Optical and electronic polarizability investigation of Nd3doped soda-lime silicate glasses," Journal of Physics and Chemistry of Solids, vol. 71, no. 7, pp. 965-970, 2010.

[27] M. H. M. Zaid, K. A. Matori, H. A. A. Sidek, B. Z. Azmi, and M. G. M. Sabri, "Effect of $\mathrm{ZnO}$ on the physical properties and optical band gap of soda lime silicate glass," International Journal of Molecular Sciences, vol. 13, no. 6, pp. 7550-7558, 2012.

[28] H. Afifi and S. Marzouk, "Ultrasonic velocity and elastic moduli of heavy metal tellurite glasses," Materials Chemistry and Physics, vol. 80, no. 2, pp. 517-523, 2003.

[29] M. K. Halimah, W. M. Daud, and H. A. A. Sidek, "Effect of AgI addition on elastic properties of quaternary tellurite glass systems," Chalcogenide Letters, vol. 7, no. 11, pp. 613-620, 2010.

[30] S. Thirumaran and N. Karthikeyan, "Structural Elucidation of Some Borate Glass Specimen by Employing Ultrasonic and Spectroscopic Studies," Journal Of Ceramics, vol. 2013, no. 1, Article ID 485317, pp. 1-10, 2013.

[31] N. Ghribi, M. Dutreilh-Colas, J.-R. Duclère et al., "Structural, mechanical and optical investigations in the TeO2-rich part of the TeO2-GeO2-ZnO ternary glass system," Solid State Sciences, vol. 40, pp. 20-30, 2015.

[32] M. Hamezan, H. A. A. Sidek, A. W. Zaidan, K. Kaida, and A. T. Zainal, "Elastic constants and thermal properties of lead-bismuth borate glasses," Journal of Applied Sciences, vol. 6, no. 4, pp. 943-949, 2006.

[33] A. G. Mostafa, M. A. Sayed, Y. B. Saddeek et al., "Studying The Elastic Properties Of Glasses Based On Ckd Using Ultrasonic Technique," And S. Arabia, vol. 10, no. 3, pp. 935-940, 2015.

[34] H. M. K, S. H. A., D. W. M. et al., "Ultrasonic study and physical properties of borotellurite glasses," American Journal of Applied Sciences, vol. 2, no. 11, pp. 1541-1546, 2005. 

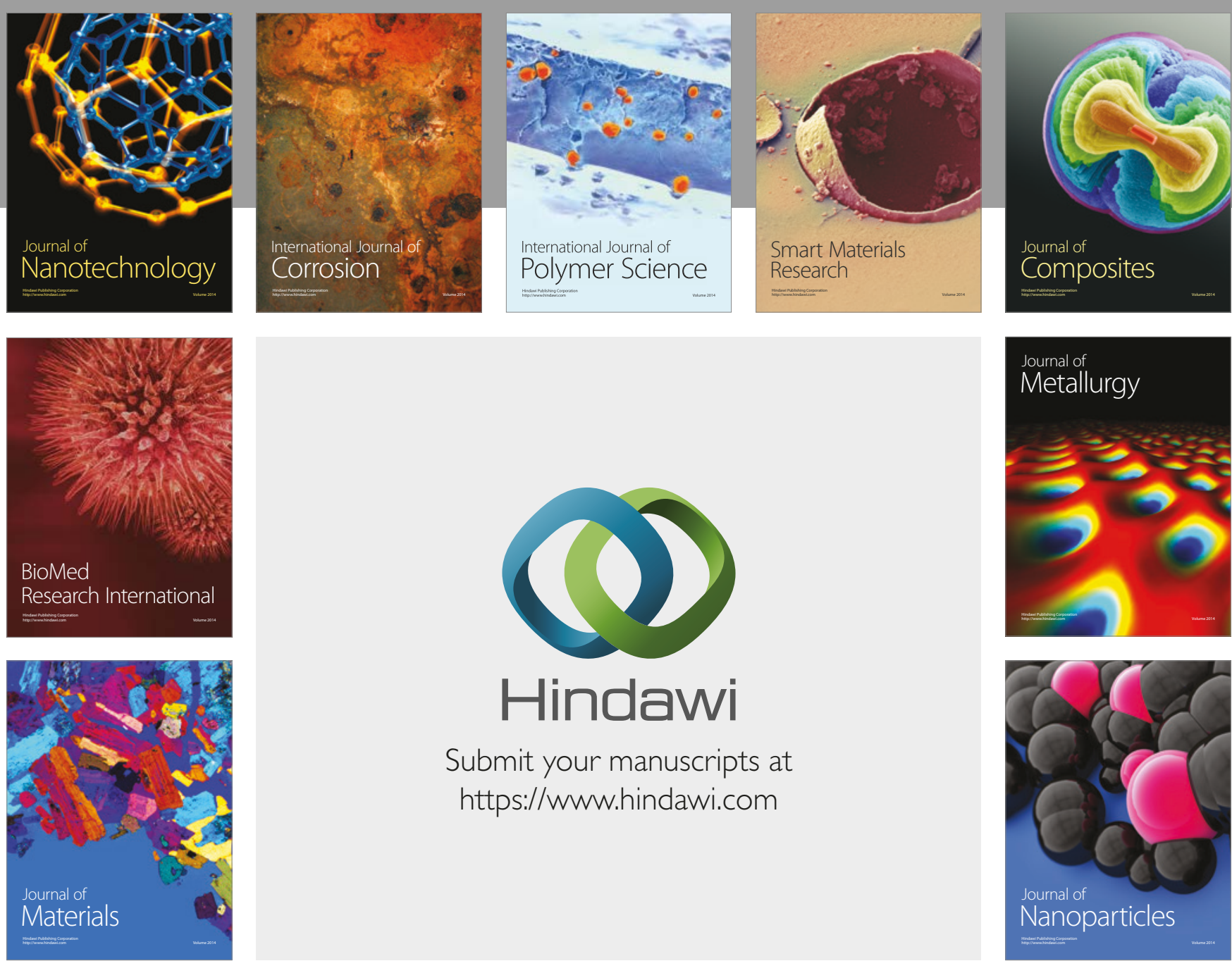

\section{Hindawi}

Submit your manuscripts at

https://www.hindawi.com
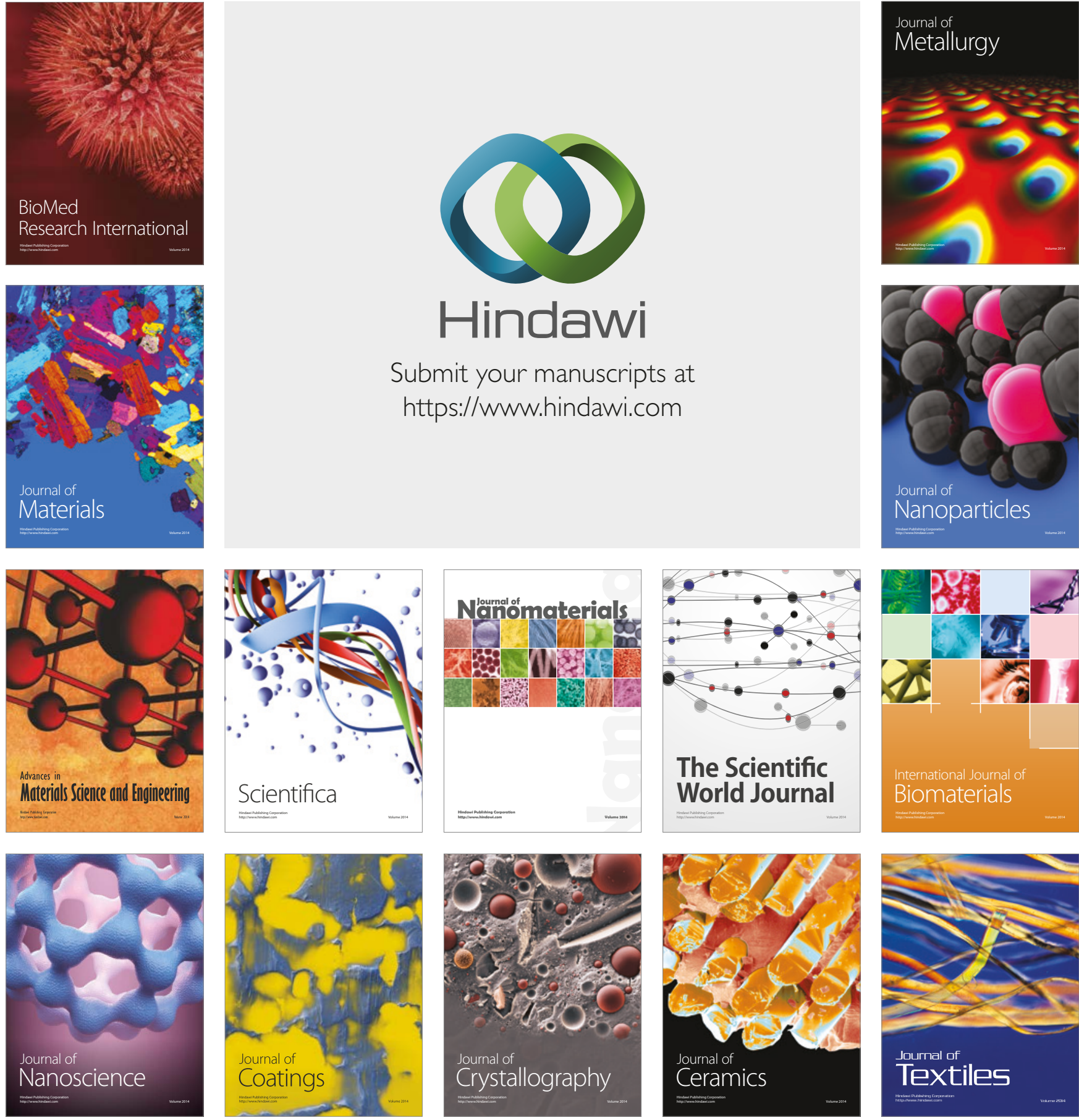

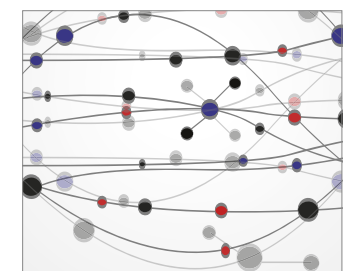

The Scientific World Journal
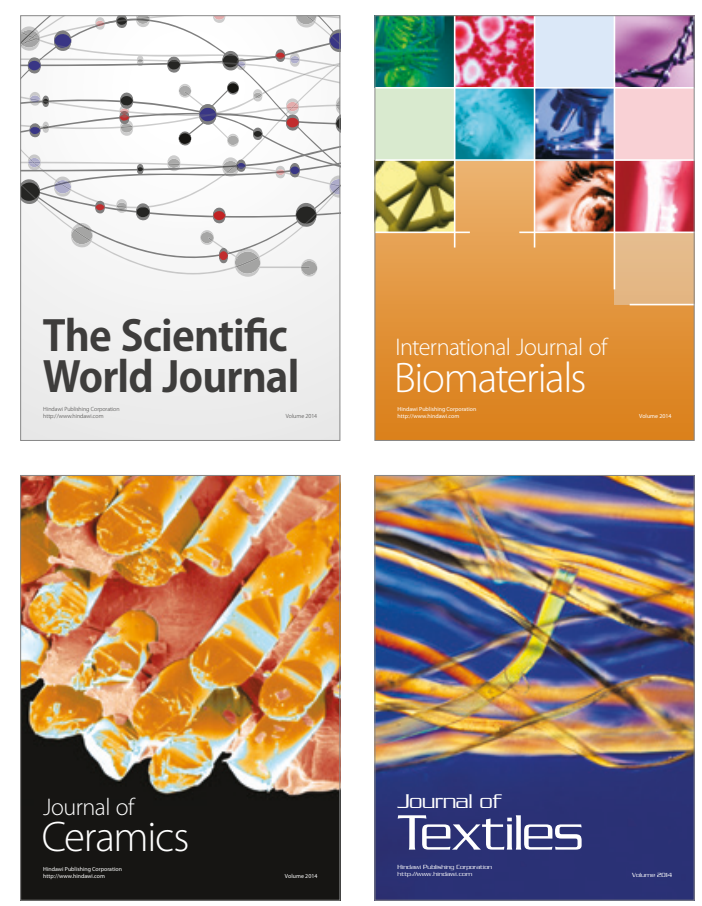